\title{
Older Members Perform Better in an Internet-Based Behavioral Weight Loss Program Compared to Younger Members
}

\author{
Marianne van der Mark ${ }^{\mathrm{a}}$ Josefine Jonasson $^{\mathrm{b}}$ \\ Stephan Rössner ${ }^{b}$ Ylva Trolle Lagerros ${ }^{a, b}$ \\ a Unit of Clinical Epidemiology, Karolinska Institutet, T2, Stockholm, \\ ${ }^{\mathrm{b}}$ Obesity Unit, Karolinska Hospital, Huddinge, Stockholm, Sweden
}

\section{Key Words}

Aging - Behavior modification - BMI - Diet - Lifestyle factors - Obesity management - Physical activity . Weight loss · Internet

\section{Summary}

Background: New technology offers increased opportunities for weight control. However, it is not clear whether older people with less computer training can make use of this tool. Our objective was to examine how members above the age of 65 years performed in an internet-based behavioral weight loss program, compared to younger members. Methods: Data from members ( $n=23,233$ ) of an internet-based behavioral weight loss program were analyzed. We restricted our study to active participants accessing the weight club, during a 6-month period (n $=4,440$ ). The number of logins, food intake, and weight records were examined. Participants were divided into age tertiles separately for men and women. The oldest tertile was further subdivided into two groups: above and below the age of 65 years. Results: Participants aged 65 or older were more likely to remain active in the weight club for at least 6 months compared to younger age groups. They had the highest frequency of recordings of food intake and current weight. Among women, those older than 65 years had on average the highest percentage of weight loss $(5.6 \mathrm{~kg}, 6.8 \%)$. Men above 65 years of age had the highest number of logins, on average 161 times during the 6-month period. Conclusion: Older participants are performing equally well or even better in an internet-based behavioral weight loss program than younger participants. Internet-based programs could be a promising and attractive option for older adults requiring assistance in losing weight.
Madeleine Svensson ${ }^{a, b} \quad$ Yvonne Linnéb

\section{Introduction}

The prevalence of obesity among older age groups is increasing in many countries [1-4]. In the USA during 2001-2002, $50 \%$ of the women and $35 \%$ of the men aged $60-69$ years sought to reduce their body weight [5]. In 2003-2004, 74\% of the men and $69 \%$ of the women aged 60 years or older were considered overweight or obese [1]. Unfortunately, the future prognoses do not foresee any major improvements [6].

Several studies have shown that voluntary weight loss in older adults decreases risk factors associated with cardiovascular diseases [7, 8], promotes physical function [9, 10], and prevents premature death [11]. The benefits of weight loss in older age groups are, however, controversial. To our knowledge, there are no ideal intervention programs established.

Until recently, most self-help material was paper-based. But with the internet, new possibilities of interactive self-help materials have evolved. Besides, internet-based weight loss programs aiming at changing behaviors have the opportunity to reach a large number of individuals at a very low cost and are in fact geographically independent. They have shown to be effective in weight reduction [12-14] and weight maintenance [15]. Additionally, weekly computerized personal feedback has shown to be as effective for losing weight as 3 months of feedback from a human e-mail counselor [16]. However, little research has been done to evaluate the effectiveness of these programs on older people with less computer training.

According to Statistics Sweden, more than $80 \%$ of the Swedish population has access to the internet, demonstrating its potential role in serving as a useful intervention tool. An internet-based behavioral weight loss program, the weight club used in this study, has been developed in collaboration with Aftonbladet, a newspaper in Sweden - which in 2005 had approximately 2 million visitors to its website daily. The knowledge, expertise and advice offered at the website are provided

Dr. Ylva Trolle Lagerros

Unit of Clinical Epidemiology

Karolinska Institutet, T2

17176 Stockholm, Sweden

Tel. +46 8-517 79183, Fax -517 79304

ylva.trolle@ki.se 
by the Obesity Unit at the Karolinska University Hospital in Stockholm, Sweden.

Due to the fact that excessive body weight is a common risk factor for many chronic diseases - and with respect to the internet's potential to promote health - it is important to examine the effectiveness of this approach in an age group, which did not grow up with computer technology. Hence, the aim of this study was to examine how older members perform in an internet-based behavioral weight loss program compared to younger members.

\section{Material and Methods}

\section{Participants}

The participants were invited through a medial advertisement campaign, informing them about the weight loss program. Interested participants had the opportunity to subscribe to a 3-, 6- or 12-month membership to access the weight club on the internet. It was possible to extend the membership at the end of the membership period. The fee of a membership plan was between EUR 33.- and EUR 55.-, favoring long-term subscription.

At the baseline of the study, all weight club members answered a questionnaire assessing sociodemographic characteristics, health status including lifestyle-related aspects, and whether or not they were willing to participate in a research study. Members agreeing to participate in the study were then asked to fill out an additional questionnaire at the initial start of the study and then once every 3rd month. Hence, all data in this study were self-reported.

The inclusion criteria in the study was membership in the weight club and completion of the additional questionnaire between September 2003 and April 2005. The excluding criteria for participation in the weight club were ages below 18 , a weight target goal below BMI of $20 \mathrm{~kg} / \mathrm{m}^{2}$, pregnancy, lactation, or medical conditions contradicting weight loss. We excluded a total of 37 participants from the data analysis who reported a starting BMI above $55 \mathrm{~kg} / \mathrm{m}^{2}$ and 7 participants who reported weight loss of more than $30 \%$ in 6 months. For most analyses, we restricted our study to those who remained active in the weight club for at least 6 months. An active participant was defined as having recorded his or her weight at least once the past month and logged in at least twice during the first 3 months, and twice during the second 3 months of membership.

\section{Weight Loss Program}

The recommended weight loss did not exceed $1 \mathrm{~kg}$ per week. The recommendations for daily energy intake were calculated using the Benedict's formula [17]. About 1,000 balanced meals and appetizing dishes were constructed based on the nutritional values found in food tables developed by the Swedish Food Agency and made accessible online to the members. New recipes were suggested every week. The participants were able to modify the dishes or to construct their own recipes, based on the food values.

The members were able to $\log$ in to the weight club's website on a 24-hour basis. Weight club members were instructed to record their food intake in the online food diary for evaluation, which automatically gave the participant instant feedback regarding energy intake and macronutrient composition. Members also had the opportunity to record their physical activity level in order to calculate their daily energy expenditure. The intensity level in metabolic equivalents (METs) of recorded activities were estimated using the Compendium of Physical Activities [18], multiplied with the total time of the activity and by the participant's weight $(\mathrm{kg})$. Members also had the opportunity to see the equivalence between the kilocalories of a certain food product and the energy expenditure of
Table 1. Descriptive ${ }^{a}$ characteristics of members in the weight club at baseline

\begin{tabular}{lll}
\hline & Men $(\mathrm{n}=3,745)$ & Women $(\mathrm{n}=19,115)$ \\
\hline Age, years & $43.2 \pm 11.7$ & $39.6 \pm 11.4$ \\
BMI, kg/m ${ }^{2}$ & $30.7 \pm 4.3$ & $29.0 \pm 5.0$ \\
Completing 6 months, \% & 21.2 & 19.1 \\
Education, \% & & \\
$\quad$ 99 years & 8.3 & 6.5 \\
10-12 years & 49.2 & 48.1 \\
$\geq 13$ years & 39.8 & 42.5 \\
$\quad$ Other & 2.6 & 2.8 \\
\hline
\end{tabular}

${ }^{\mathrm{a}}$ Mean $\pm \mathrm{SD}$.

a chosen physical activity. Members were advised to weigh themselves and record their weight once a week on the website. During the program, a data file consisting data of the participants' online activities, including their frequency of logins, frequency of recordings of weight and food intake, overall usage of food diary, and weight status, was collected and sent to the researchers by the weight club coordinators.

Furthermore, members could participate in an online chat called 'the Meeting Point' to exchange knowledge and experiences with the program with other members and to obtain peer support for their efforts in losing weight. Each member had a personal blog accessible to other members. Approximately $25 \%$ of all members used this feature. Additionally, members could participate in chats with experts of varying backgrounds including physicians, dieticians, nurses, physiotherapists, psychologists etc., answering questions 5 times a week, 30 min each session. Answers to selected questions were published weekly on the website and in the newspaper. The newspaper in printed and electronic form highlighted news reaching media attention, such as 'new' trendy diets, miracle cures etc., together with comments from the experts. Successful members were interviewed about their experience and methods applied, and the information was posted on the website. Standard letters aiming at coaching and encouraging the participants to further engage in the program were sent automatically throughout the process of the program.

The Ethics Committee of the Karolinska Institute approved the study. The participants remained anonymous, and all information was kept confidential to all parties.

\section{Statistics}

Of the total sample size $(n=23,233)$, representing $23 \%$ of all the members of the weight club, 22,860 filled out complete information about gender, age, height, and weight (table 1). Out of these, 4,440 participants qualified as active members.

The active participants were divided into age tertiles separately for men and women. They were then compared to one another with respect to their progress in the program during the 6-month period using the Pearson chi-square test. Since the data was not normally distributed, the nonparametric Kruskal-Wallis test was used to compare weight reduction and overall participation level in the weight club among the 4,440 active members of the age tertiles.

We used the Mann-Whitney test to examine the results in relation to the Swedish ordinary retirement age of 65 years. Thus we further divided the participants in the oldest tertile into two subgroups, above and below the age of 65 . Differences between the groups were considered to be significant when the $\mathrm{p}$ value was less than 0.05 .

Finally, we used Pearson correlation coefficient to study the correlation between baseline BMI and weight loss percentage and Spearman correction coefficient to evaluate the correlation between physical activity level at baseline and weight loss percentage. All analyses were performed using SPSS 15.0 for Windows (SPSS Inc, Chicago, IL, USA). 


\section{Results}

The mean age of the 22,860 study participants was 40.2 years, and the average BMI was $29.3 \mathrm{~kg} / \mathrm{m}^{2}$. In contrast, the average age and BMI among the members not agreeing to participate were 41.6 years and $28.6 \mathrm{~kg} / \mathrm{m}^{2}$ respectively [19]. More than $80 \%$ of the participants were women. The characteristics of the participants are described in table 1 . Men were older, less educated, had a higher starting BMI, and were more prone to be active in the weight club during at least a 6-month period, compared to women.

A total of 793 men and 3,647 women were defined as active members. For both men and women, the participants in the oldest age tertiles had the highest percentage of members remaining active for at least 6 months ( $p<0.001$; fig. 1$)$. When participants of the oldest tertile were divided into groups, below and above 65 years of age, the oldest participants were still the most active group although this was not shown to be significant for men (women $\mathrm{p}<0.001$, men $\mathrm{p}=0.365$; fig. 1 ).

Moreover, for women, the participants aged 65 or older had on average the highest percentage of weight loss $(6.8 \%)$ compared to younger women. Men had a higher weight loss percentage compared to women irrespective of age. Men aged 38 49 years had the highest mean weight loss of $7.7 \%$ (table 2 ).

Participants older than 65 years of both sexes recorded most frequently their current weight and food intake in their diary (table 2). Also, the highest number of logins was seen in the participants above the age of 65 years in both men and women: men aged $65-83$ years logged in on average 161 times during the 6-month period.

The results further showed that there was only a weak correlation $(\mathrm{p}<0.001)$ between baseline BMI and weight loss percentage for women (correlation coefficient $=0.08$ ) and for men (correlation coefficient $=0.14$ ). Furthermore, no significant differences in starting BMI existed.

The oldest tertiles for both men and women reported a higher leisure time activity level at baseline than younger tertiles. Among men in the oldest tertile, $64.8 \%$ engaged in 4-6 h of leisure time physical activity per week, while $57.2 \%$ of the men in the youngest tertile had this level of exercise. For women, the numbers were 69.2 versus $63.4 \%$. Those over the age of 65 reported an even higher degree of leisure time physical activity, where $74.4 \%$ of the men and $77.3 \%$ of the women reached the level of 4-6 h a week. No significant correlations between physical activity level at baseline and total weight loss in percentage were found.

\section{Discussion}

In this study, we examined how older members, particularly those above the age of 65 , performed in an internet-based behavioral weight loss program compared to younger members. We found that older participants performed equally well
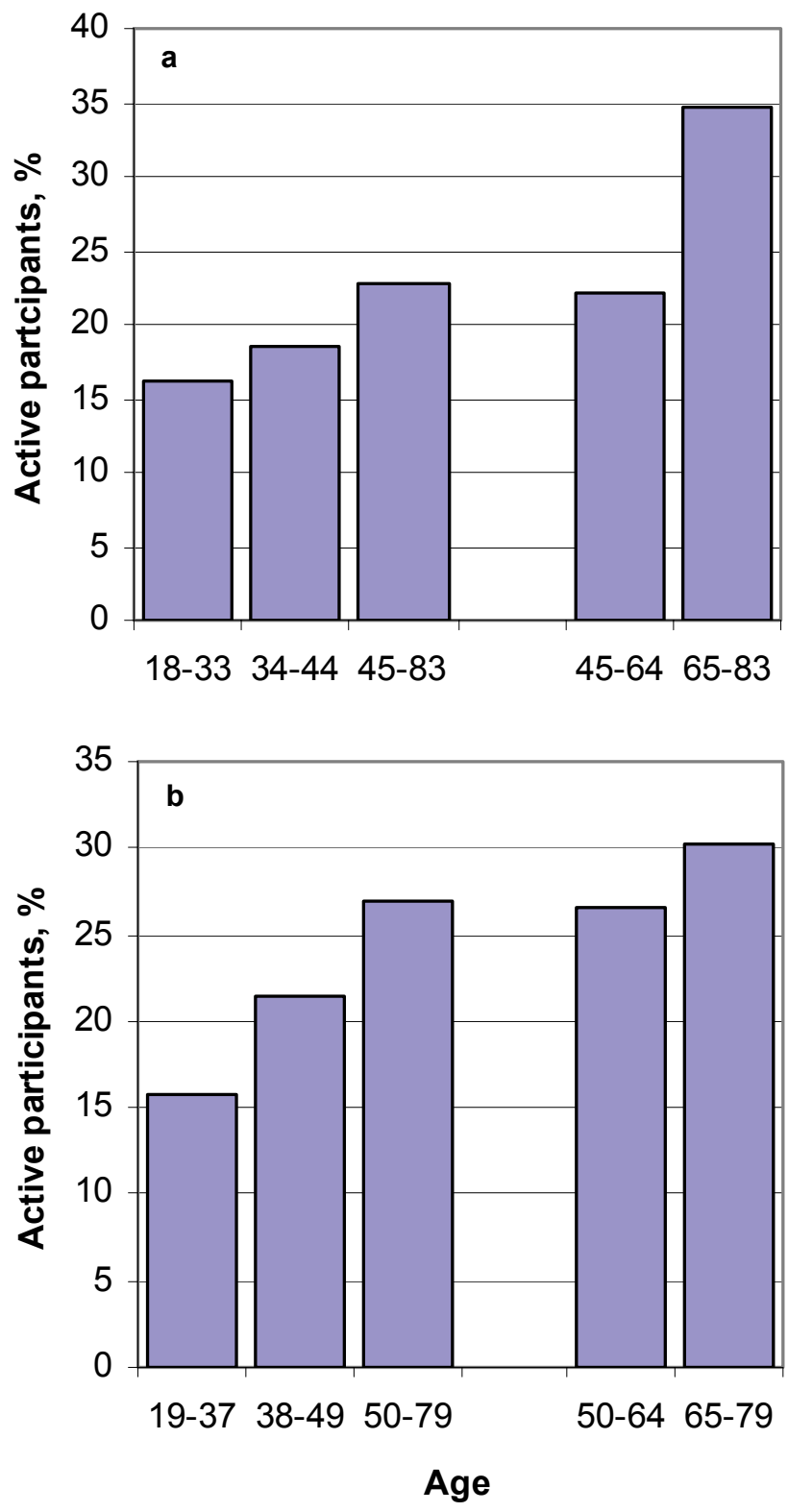

Fig. 1. Active members accessing the weight club during a 6-month period, by age group. Members are divided into age tertiles and the oldest tertile is further subdivided into above and below the age of 65 . a Women; b men.

or even better than younger participants in the weight club. Older participants were more likely to be active in the weight club during the 6-month period compared to younger participants: they logged in and recorded their diet and current weight more frequently.

An earlier study by our research team found an association between participants spending more time watching television per week at baseline and greater weight loss in the weight club [20] - a result that may imply similar consequences in our study. In fact, the older participants' additional spare time could mean a higher involvement in the weight loss club, indicating that these participants spend an equivalent time using 
Table 2. Comparison of the age groups on success and activity in the weight club $(n=4,440)$

\begin{tabular}{|c|c|c|c|c|c|c|c|}
\hline & \multicolumn{4}{|c|}{ Sex-specific age tertiles, mean \pm SD } & \multicolumn{3}{|c|}{ Above/below the age of 65, mean $\pm \mathrm{SD}$} \\
\hline & $\begin{array}{l}\text { 18-33 years } \\
(\mathrm{n}=1,068)\end{array}$ & $\begin{array}{l}34-44 \text { years } \\
(\mathrm{n}=1,166)\end{array}$ & $\begin{array}{l}45-83 \text { years } \\
(\mathrm{n}=1,413)\end{array}$ & $\mathrm{p}$ value ${ }^{\mathrm{a}}$ & $\begin{array}{l}\text { 45-64 years } \\
(\mathrm{n}=1,312)\end{array}$ & $\begin{array}{l}65-83 \text { years } \\
(\mathrm{n}=101)\end{array}$ & $\mathrm{p}$ value $\mathrm{b}^{\mathrm{b}}$ \\
\hline \multicolumn{8}{|l|}{ Women } \\
\hline Weight loss, $\mathrm{kg}$ & $4.32 \pm 4.5$ & $4.95 \pm 4.5$ & $4.90 \pm 4.0$ & $<0.001$ & $4.85 \pm 4.1$ & $5.57 \pm 3.5$ & 0.043 \\
\hline Weight loss, \% & $5.35 \pm 5.2$ & $5.93 \pm 5.1$ & $5.99 \pm 4.7$ & 0.003 & $5.93 \pm 4.8$ & $6.78 \pm 4.1$ & 0.064 \\
\hline Log-ins & $145.0 \pm 126$ & $132.8 \pm 117$ & $133.0 \pm 115$ & 0.134 & $131.8 \pm 115$ & $148.6 \pm 117$ & 0.023 \\
\hline Diary records & $67.8 \pm 38.1$ & $70.8 \pm 41.7$ & $76.0 \pm 42.7$ & $<0.001$ & $74.7 \pm 42.5$ & $93.4 \pm 42.3$ & $<0.001$ \\
\hline \multirow[t]{2}{*}{ Weight records ${ }^{c}$} & $\begin{array}{l}15.0 \pm 5.5 \\
(\mathrm{n}=740)\end{array}$ & $\begin{array}{l}16.0 \pm 5.7 \\
(\mathrm{n}=878)\end{array}$ & $\begin{array}{l}16.9 \pm 5.4 \\
(n=1,093)\end{array}$ & $<0.001$ & $\begin{array}{l}16.8 \pm 5.4 \\
(\mathrm{n}=1,018)\end{array}$ & $\begin{array}{l}19.0 \pm 4.8 \\
(\mathrm{n}=75)\end{array}$ & $<0.001$ \\
\hline & $\begin{array}{l}\text { 19-37 years } \\
(\mathrm{n}=203)\end{array}$ & $\begin{array}{l}38-49 \text { years } \\
(\mathrm{n}=274)\end{array}$ & $\begin{array}{l}\text { 50-79 years } \\
(\mathrm{n}=316)\end{array}$ & & $\begin{array}{l}50-64 \text { years } \\
(\mathrm{n}=276)\end{array}$ & $\begin{array}{l}\text { 65-79 years } \\
(\mathrm{n}=40)\end{array}$ & \\
\hline \multicolumn{8}{|l|}{ Men } \\
\hline Weight loss, $\mathrm{kg}$ & $6.88 \pm 6.1$ & $7.89 \pm 5.4$ & $6.50 \pm 4.7$ & 0.002 & $6.44 \pm 4.6$ & $6.94 \pm 4.8$ & 0.766 \\
\hline Weight loss, \% & $6.70 \pm 5.8$ & $7.67 \pm 5.0$ & $6.57 \pm 4.5$ & 0.011 & $6.53 \pm 4.5$ & $6.84 \pm 4.4$ & 0.923 \\
\hline Log-ins & $137.5 \pm 108$ & $137.7 \pm 129$ & $146.2 \pm 119$ & 0.433 & $144.1 \pm 114$ & $160.7 \pm 152$ & 0.710 \\
\hline Diary records & $65.8 \pm 39.8$ & $72.9 \pm 42.7$ & $83.5 \pm 49.6$ & $<0.001$ & $82.6 \pm 48.8$ & $89.2 \pm 54.0$ & 0.437 \\
\hline Weight records ${ }^{c}$ & $\begin{array}{l}14.9 \pm 5.3 \\
(n=141)\end{array}$ & $\begin{array}{l}17.1 \pm 5.5 \\
(\mathrm{n}=189)\end{array}$ & $\begin{array}{l}18.0 \pm 5.5 \\
(\mathrm{n}=232)\end{array}$ & $<0.001$ & $\begin{array}{l}17.7 \pm 5.4 \\
(\mathrm{n}=202)\end{array}$ & $\begin{array}{l}19.8 \pm 5.7 \\
(\mathrm{n}=30)\end{array}$ & 0.098 \\
\hline
\end{tabular}

${ }^{a} \mathrm{p}$ value from Kruskal-Wallis test.

${ }^{\mathrm{b}} \mathrm{p}$ value from Mann-Whitney test.

'Information on number of weight records was not available for 1,167 participants.

the internet. It should be noted that both men and women above the age of 65 reported a higher physical activity level at baseline compared to younger participants. However, no correlations between physical activity level at baseline and total weight loss in percentage were found. Furthermore, there was only a weak correlation between starting BMI and weight loss. Thus, these factors could not explain the better results found among the older age groups.

More than $80 \%$ of the study participants were women. This is in accordance with the well-known fact that more women than men are trying to lose weight, irrespective of sociodemographic status and BMI category [5]. These results may not only mirror the societal pressure of possessing a slim body, even at a higher age, but it could also reflect women's higher enthusiasm of using an internet-based weight loss method.

This study could not explain why men aged 38-49 years had the highest percentage of weight loss. For women, however, this was found in those above the age of 65 - the group who logged in, completed their diary, and recorded their weight most frequently.

One of the strengths of this study was the large sample size. Although only $23 \%$ of the total members of the weight club agreed to participate in the research study, the total sample size still represents one of the largest in terms of internetbased weight loss intervention studies. Yet, there could be a selection bias regarding the difference between members willing to participate in the scientific study and those who did not: the participants had a slightly higher BMI than the non-participants. More motivated members may have a higher self- efficacy to make the change needed to lose weight and as a result may have been more likely to participate in our study. This, in turn, may have generated a greater overall weight loss and activity level of the members as assessing the weight club members as a whole. Moreover, the weight club has been elected as the best Swedish website for weight loss, both in terms of technical aspects and its user-friendly setup. To date, the weight club has been comprised of a total of 350,000 Swedish members. It has expanded worldwide and is now operating in six other countries.

Since the general health care system has a limited capacity to treat people with weight problems in most countries, an internet-based weight loss program could be a practical and effective way to offer guidance. The internet offers a variety of possible applications that can be added to programs encouraging weight loss. In this way a large quantity of people suffering from being overweight or obese could be helped in a very cost-effective way. This should not be seen as a substitution but rather as an addition to the general health care. Individuals benefiting most from intervention approaches like these would be those on waiting lists, not having enough time or money to seek professional help, living too far from the general health care, or aiming at losing only a few percentages of their total body weight.

One of the limitations of the study was that the internetbased program did not register the precise activities of the participants, once they had logged in to the website. This information could have added valuable knowledge by examining the various sources that the participants used on 
the website. For example, more information about how the participants used their online food diary as well as the duration and frequency of exercise throughout their participation in the club, would have been valuable in order to understand possible influencing factors of weight loss. This may be taken into consideration if future interventions are being launched. It did nevertheless offer the possibility to receive information about the number of logins, current weight records, and usage of the food intake diary.

Furthermore, the reliance on self-reported data was a disadvantage in our study. Reported claims on weight loss by the participants were not verified. Participants may have provided false or inaccurate data, but there is no particular reason why members would misreport systematically since they entered the weight club entirely for their own benefit.

The weight club was in the first place launched as a program to help a large number of people losing weight, rather than to support a research study. Thus, the participants constituted a convenience sample answering our ad, and not a random sample of the population. Moreover, approximately $40 \%$ of the study participants had more than 12 years of education, compared to $30 \%$ of the Swedish population (according to Statistics Sweden). As the main objective of this study was to examine the older participants' progress in the weight club, we do not expect this difference to bias our results. However, the low percentage of participants aged 65 or older suggests a selective sample of the older aged participants, which in turn may have contributed to the good results in the weight club among this age group.

Also, since information about weight loss is widely distributed in newspapers, magazines, and in the society as a whole, it is difficult to determine to what degree the participants were exposed to other information sources focusing on weight loss, and how it has affected their weight. Lastly, it should be noted that the participants' usage of weight loss medications was not documented, and therefore we could not stratify on this, but we excluded participants with more than $30 \%$ weight loss in 6 months.

Only $19 \%$ of the participants remained active in the weight club for at least 6 months. One possible reason for the loss of participants could potentially be the participants' high level of satisfaction of the weight they already had lost during their program participation - they withdrew as a result of reaching target weight. However, the dropout percentage is comparable to those found in some earlier studies assessing internetbased weight loss programs $[13,14]$
High rates of attrition was a limitation in our study - a common problem not only for internet-based interventions but also in general [21]. On the other hand, a high attrition rate may not undermine the potential usefulness of online interventions as the marginal cost per user is quite low [22].

Suggestions on how to prevent high attrition rates could be to allow the participants to freeze their membership and to unfreeze it again when suitable for the participant. Flexibility is an important aspect which has shown to be one of the most effective approaches to prevent attrition [23]. Although our weight loss program uses a multidimensional approach which focuses on motivational techniques to accomplish appropriate weight loss, further aspects of being flexible to the participants could be added. For example, introducing more personalized feedback might improve adherence to the program. The coaches, or experts, could correspond via e-mail or chat on a one-to-one basis with the participants. This would not only allow for continuous updates about the members' progression but also tailor health information to the participants' individual needs.

Internet usage among older age groups is in general lower than among younger age groups; however, older age groups are certainly a target group for future internet applications $[24,25]$. Internet-based weight loss programs offer several advantages to the aged population. For example, text could be enlarged, illustrations and sounds could clarify concepts, and the pace at which the participant navigates the page could be adjusted accordingly. The intervention can be used at home, at any time of day or night, and the participants have the opportunity to receive social support without requiring leaving home, which could be an advantage for older individuals. Programs of this type may thus have the potential to reach a large number of obese elderly who otherwise might not seek help.

In conclusion, our study showed that people above the age of 65 years who participated in the internet-based weight loss program were performing equally well or even better than the younger members. Hence, internet-based programs could serve as a promising, attractive and cost-effective alternative for older adults requiring losing weight in order to achieve a higher quality of life.

\section{Disclosure}

The authors declared no conflict of interest.

\section{References}

1 Ogden CL, Carroll MD, Curtin LR, McDowell MA, Tabak CJ, Flegal KM: Prevalence of overweight and obesity in the United States, 1999-2004. JAMA 2006;295:1549-1555.

2 Sulander T, Rahkonen O, Helakorpi S, Nissinen A, Uutela A: Eighteen-year trends in obesity among the elderly. Age Ageing 2004;33:632-635.
3 Sundquist K, Qvist J, Johansson SE, Sundquist J: Increasing trends of obesity in Sweden between 1996/97 and 2000/01. Int J Obes Relat Metab Disord 2004;28:254-261.

4 Rodriguez Artalejo F, Lopez Garcia E, GutierrezFisac JL, Banegas Banegas JR, Lafuente Urdinguio PJ, Dominguez Rojas V: Changes in the prevalence of overweight and obesity and their risk factors in Spain, 1987-1997. Prev Med 2002;34:72-81.

5 Weiss EC, Galuska DA, Khan LK, Serdula MK: Weight-control practices among U.S. adults, 20012002. Am J Prev Med 2006;31:18-24.

6 Arterburn DE, Crane PK, Sullivan SD: The coming epidemic of obesity in elderly Americans. J Am Geriatr Soc 2004;52:1907-1912. 
7 Villareal DT, Miller BV 3rd, Banks M, Fontana L, Sinacore DR, Klein S: Effect of lifestyle intervention on metabolic coronary heart disease risk factors in obese older adults. Am J Clin Nutr 2006;84:1317-1323.

8 Colman E, Katzel LI, Rogus E, Coon P, Muller D, Goldberg AP: Weight loss reduces abdominal fat and improves insulin action in middle-aged and older men with impaired glucose tolerance. Metabolism 1995;44:1502-1508.

$\checkmark 9$ Villareal DT, Banks M, Sinacore DR, Siener C, Klein S: Effect of weight loss and exercise on frailty in obese older adults. Arch Intern Med 2006;166: 860-866.

10 Miller GD, Nicklas BJ, Davis C, Loeser RF, Lenchik L, Messier SP: Intensive weight loss program improves physical function in older obese adults with knee osteoarthritis. Obesity (Silver Spring) 2006;14: 1219-1230.

11 Wannamethee SG, Shaper AG, Lennon L: Reasons for intentional weight loss, unintentional weight loss, and mortality in older men. Arch Intern Med 2005; 165:1035-1040.

12 McCoy MR, Couch D, Duncan ND, Lynch GS: Evaluating an internet weight loss program for diabetes prevention. Health Promot Int 2005;20: 221-228.
13 Rothert K, Strecher VJ, Doyle LA, Caplan WM, Joyce JS, Jimison HB, Karm LM, Mims AD, Roth MA: Web-based weight management programs in an integrated health care setting: a randomized, controlled trial. Obesity (Silver Spring) 2006;14: 266-272.

14 Tate DF, Wing RR, Winett RA: Using internet technology to deliver a behavioral weight loss program. JAMA 2001;285:1172-1177.

15 Harvey-Berino J, Pintauro S, Buzzell P, Gold EC: Effect of internet support on the long-term maintenance of weight loss. Obes Res 2004;12:320-329.

16 Tate DF, Jackvony EH, Wing RR: A randomized trial comparing human e-mail counseling, computer-automated tailored counseling, and no counseling in an internet weight loss program. Arch Intern Med 2006;166:1620-1625.

17 Harris JA, Benedict F: A biometric study of human basal metabolism. Proc Natl Acad Sci U S A 1918;4: 370-373.

18 Ainsworth BE, Haskell WL, Leon AS, Jacobs DR Jr, Montoye HJ, Sallis JF, Paffenbarger RS Jr: Compendium of physical activities: classification of energy costs of human physical activities. Med Sci Sports Exerc 1993;25:71-80.
19 Jonasson J: Weight loss programmes over the internet - opportunities and limitations. In thesis from the Department of Medicine, Stockholm, Karolinska Institutet, 2007.

20 Jonasson J, Linne Y, Neovius M, Rossner S: An internet-based weight loss programme - a feasibility study with preliminary results from 4209 completers. Scand J Public Health 2009;37:75-82.

21 Couper MP, Peytchev A, Strecher VJ, Rothert K, Anderson J: Following up nonrespondents to an online weight management intervention: randomized trial comparing mail versus telephone. J Med Internet Res 2007;9:e16.

22 Eysenbach G: The law of attrition. J Med Internet Res 2005;7:e11.

23 Coday M, Boutin-Foster C, Goldman Sher T, Tennant J, Greaney ML, Saunders SD, Somes WG Strategies for retaining study participants in behavioral intervention trials: retention experiences of the NHI behavior change consortium. Ann Behav Med 2005;29(suppl):55-65.

24 Adams N, Stubbs D, Woods V: Psychological barriers to internet usage among older adults in the UK. Med Inform Internet Med 2005;30:3-17.

25 Eastman JK, Lyer R: The elderly's uses and attitudes towards the internet. J Consum Market 2004;21: 208-220. 